\title{
Evaluation of the National Swiss Skin Cancer Screening Campaign 2013: Do We Do the Right Thing?
}

\author{
Ralph-Peter Braun ${ }^{a}$ Karina Ulrich ${ }^{a}$ Robert Hunger ${ }^{b}$ Olivier Gaide ${ }^{c}$ \\ Andreas Arnold $^{d}$ Rastine Merat ${ }^{\mathrm{e}}$ Reinhard Dummer ${ }^{\mathrm{a}}$ Jürg Hafner ${ }^{\mathrm{a}}$ \\ Lars E. French ${ }^{\mathrm{a}}$ Antonio Cozzio ${ }^{\mathrm{a}} \mathrm{f}$ \\ a Department of Dermatology, University of Zurich, Zurich, ${ }^{\mathrm{b}}$ Department of Dermatology, University of Bern, Bern, \\ 'Department of Dermatology, University of Lausanne, Lausanne, ${ }^{\mathrm{d}}$ Department of Dermatology, University of Basel, \\ Basel, ${ }^{e}$ Department of Dermatology, University of Geneva, Geneva, and ${ }^{\mathrm{f} D e p a r t m e n t}$ of Dermatology, Kantonsspital \\ St. Gallen, St. Gallen, Switzerland
}

\section{Keywords}

Skin cancer screening $\cdot$ Skin cancer $\cdot$ Melanoma $\cdot$ Secondary prevention $\cdot$ Basal cell carcinoma $\cdot$ Euromelanoma grams compare favorably with the prevented potential therapeutic costs of late-stage melanoma. The low response rate of screenees agreeing to be followed up limits conclusions of this study.

(c) 2017 S. Karger AG, Basel

\begin{abstract}
Background: Skin cancer prevention and screening programs are performed in many countries. Their benefit is discussed controversially. Objective: Our aim is to evaluate the Skin Cancer Screening Program 2013 in Switzerland by following up screenees upon interventions. Methods: Quality was assessed by personal follow-up via phone/e-mail of every patient that had been screened during this campaign and histological follow-up of all participants with suspicious skin lesions. Results: Of the 1,087 screenees requiring interventions, 263 agreed to participate in the follow-up. We were able to obtain 66 histology reports. During this campaign 33 malignant lesions (8 melanomas) were removed. Conclusion: The overall melanoma detection rate in our free Skin Cancer Screening Program is comparable to those in European public activities. The costs of free screening pro-
\end{abstract}

\section{KARGER}

(C) 2017 S. Karger AG, Basel

E-Mail karger@karger.com

www.karger.com/drm

\section{Introduction}

Switzerland has the highest incidence of melanoma in Europe and a long tradition in participating in skin cancer prevention campaigns. Since 2001, a National Skin Cancer Screening Day has been organized by the Swiss Society of Dermatology and Venereology on a yearly basis. In order to enhance its impact, the campaign was accompanied by intense media coverage and other activities such as public seminars. On this particular day, participating dermatologists (both in private practice and hospitals) offered free skin cancer screening examinations. The campaign was performed as a collaboration of the Swiss Society for Dermatology and Venereology, the Eu-

Ralph Peter Braun

Department of Dermatology, University Hospital Zurich Gloriastrasse 31

CH-8091 Zurich (Switzerland)

E-Mail Ralph.braun@usz.ch 


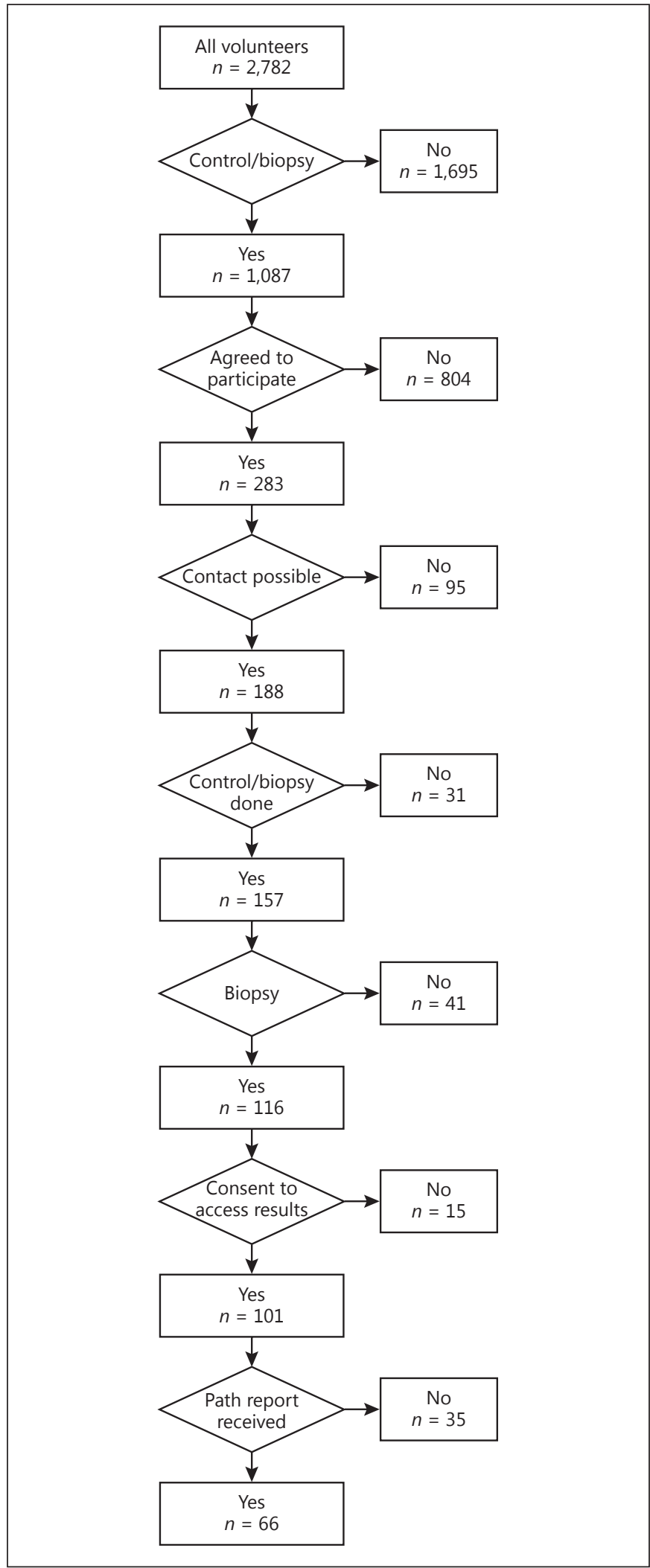

Fig. 1. Flowchart of Methods. Workflow follow-up of participants of the Swiss Melanoma Day 2013. romelanoma Initiative, and the Swiss Cancer League. In 2013, 86 dermatologists (in private practice and 5 university hospitals) participated in this campaign. The participants were free to decide whether they wanted to see the patients based on appointments or whether the patients could present themselves at their practice without an appointment (open house consultations). During the screening, clinical total body examination and dermoscopy of suspect lesions were performed. All participating dermatologists were volunteers and were seeing patients free of charge. The objective of this study was to evaluate the Skin Cancer Screening Program 2013 in Switzerland by following up screenees upon interventions.

\section{Methods}

For further details, see the online supplementary material (see www.karger.com/doi/10.1159/000484946 for all online suppl. material) (Fig. 1).

\section{Results}

In 2013, 86 dermatologists (in private practice and 5 university hospitals) participated in this campaign. All geographic and 4 language regions of Switzerland were represented. The complete workflow is shown in Figure 1. A total of 2,782 questionnaires were collected. Out of all the patients who were seen during this campaign, $1,695(60.9 \%)$ required no further action. In 1,087 patients, the physician performing the screening examination recommended either a control visit $(n=685,24.6 \%$ of 2,782 screens) or a biopsy/excision ( $n=402,14.5 \%)$. Of these 1,087 patients, 804 (73.9\%) did not agree to be contacted 6 months later for the purpose of quality assessment; 283 patients agreed to be contacted and provided anonymous contact details (phone number or e-mail address). Of these 283 patients who agreed to participate, we were able to contact 188 of them after 6 months. In 5 cases the contact information was not correct (i.e., phone number not working or incorrect e-mail address), and in 90 cases the patients did not reply ( 39 by phone, 51 by e-mail). Of the 188 remaining patients, 31 (16.5\%) stated not to have followed the recommendations from the screening visit (control or biopsy), and 41 (21.8\%) had a control visit as proposed, but there was no further treatment required. Of the remaining 116 patients, 15 answered that a biopsy was performed, but they did not agree to communicate the results.
2
Dermatology

DOI: $10.1159 / 000484946$
Braun/Ulrich/Hunger/Gaide/Arnold/ Merat/Dummer/Hafner/French/Cozzio 
We ended up with 101 patients with an excision agreeing to communicate the results. Of these 101 patients, we were able to get an anonymized copy of their pathology report in 66 cases. In the remaining 35 cases we were not able to access this information even though the patients had agreed to share this information with us and they had contacted their physicians.

Analysis of the 66 evaluable cases revealed the following diagnoses: 8 melanomas, 17 basal cell carcinomas, 4 squamous cell carcinomas, 4 malignant skin tumors of other type, 11 dysplastic nevi, and 5 actinic keratosis (Table 1). Dysplastic nevi in our definition are lesions which clinically and dermoscopically look atypical but which lack histological hallmarks of melanoma. Detailed information regarding the 8 melanomas can be found in Table 2. The average tumor thickness was $1.02 \mathrm{~mm}$ (median 0.65 ; range $0.42-3.3$ ).

The description of the epidemiological data is based on the 283 patients who required follow-up or biopsy and who agreed to participate in this anonymous evaluation. The majority of participants were females (54.8\%) aged between 50 and 75 years (50.5\%). The average/median ages were $62 / 66$ years for male and 53/56 years for female participants. The majority lived in a partnership (70.3\%). Overall, $70.3 \%$ came for prevention and $25.4 \%$ because they were concerned about a specific lesion; $12 \%(7 / 66)$ had more than 100 nevi, and 2 of the 8 melanoma patients were among this group (25\%). The predominant skin type was type $2(30.4 \%)$. The results of the epidemiological data are summarized in Table 3 .

A total of 48 of the 66 participants $(72.7 \%)$ who required an excision/biopsy came for prevention reasons only. They were not concerned about a specific lesion themselves. In the group of histologically proven melanomas, this was the case for 4 out of 8 patients (50\%), indicating that half of the participants diagnosed with melanoma did not suspect this at all when they attended for screening.

In our series, the positive predictive value for melanoma, i.e., the ratio of true positives (melanoma) and positive calls (dermoscopic suspicion) was $8 / 11(0.73)$. The detection rate for melanoma in the entire test set was $8 / 2,782$ screenees, resulting in a detection rate of $0.29 \%$.

\section{Discussion}

We have analyzed the data of 66 fully assessed screenees of our Annual Skin Cancer Prevention Day. If we extrapolate the results of the 66 patients with full analysis to the

National Swiss Skin Cancer Screening

Campaign 2013
Table 1. Distribution of the diagnoses of the 66 histologies we were able to track down, as well as the estimates for all 402 performed biopsies

\begin{tabular}{lcc}
\hline Diagnosis & $\begin{array}{l}\text { Distribution } \\
(n=66)\end{array}$ & $\begin{array}{l}\text { Estimate } \\
(n=402)\end{array}$ \\
\hline Benign & 12 & 73 \\
Benign nevi & 5 & 30 \\
Seborrheic keratosis & 5 & 30 \\
Actinic keratosis & 11 & 67 \\
Dysplastic nevi & 33 & 201 \\
\hline Total benign & 8 & 49 \\
\hline Malignant & 17 & 104 \\
Melanoma & 4 & 24 \\
Basal cell carcinoma & 4 & 24 \\
Squamous cell carcinoma & 33 & 201 \\
Other & 66 & 402 \\
\hline Total malignant & & \\
\hline Total & & \\
\hline
\end{tabular}

Table 2. Subtypes of the histologically proven melanomas with tumor thickness $(n=8)$

\begin{tabular}{ll}
\hline Melanoma subtype & Thickness, $\mathrm{mm}$ \\
\hline Lentigo maligna melanoma & 0.6 \\
Spitzoid malignant melanoma & 0.7 \\
Superficial spreading melanoma & 0.42 \\
Malignant melanoma & 3.3 \\
Superficial spreading melanoma & 1.39 \\
Nodular malignant melanoma & 1.41 \\
Melanoma in situ & 0 \\
Superficial spreading melanoma & 0.35
\end{tabular}

The average thickness was $1.02 \mathrm{~mm}$ (median 0.65).

Table 3. Reasons for participation in skin cancer screening among all proven biopsy cases versus all histologically proven melanoma cases

\begin{tabular}{lll}
\hline Reason for screening & $\begin{array}{l}\text { Proven } \\
\text { biopsies }\end{array}$ & $\begin{array}{l}\text { Proven } \\
\text { melanomas }\end{array}$ \\
\hline Prevention & 48 & 4 \\
Patient concern & 8 & 1 \\
History of skin cancer & 1 & 1 \\
Family history & 3 & 0 \\
Sent by relative & 2 & 0 \\
Other reason & 3 & 2 \\
No answer & 1 & 0 \\
\hline Total & 66 & 8 \\
\hline
\end{tabular}

Dermatology

DOI: $10.1159 / 000484946$ 
402 screenees receiving initial recommendation to perform further analysis/excision, we predict a detection of 49 melanomas (12.2\% of 402$), 103$ basal cell carcinomas (25.6\% of 402 ), and 24 squamous cell carcinomas ( $6 \%$ of 402). Given the morbidity, mortality, and the financial impact on health costs of skin cancer, we may assume that such a National Screening Day does have a positive impact. All screening physicians in this campaign were volunteers and did not receive any reimbursement for this, but assuming an average cost of screening (outside this campaign) per case in Switzerland of CHF 120 (EUR 100 ), the costs for screening 2,782 individuals would be CHF 300,000 (EUR 280,000) (costs are hypothetical since the dermatologists have been participating in this campaign without charge). Even though we are not able to formally prove it, we believe that this is an acceptable sum compared with the potential cost of only 5 missed melanomas with consecutive dissemination and indication for therapy in their advanced stage using modern checkpoint inhibitor therapies which annually cost up to more than EUR 100,000 per patient in Switzerland. Given the current costs of advanced-stage melanoma therapies, and those of primary and secondary prevention, the two goals of the campaign are warranted [1]. While routine screening for early detection of skin cancer is not currently recommended, screening of individuals at increased risk for melanoma appears cost-effective [2].

A total of 2,782 individuals were screened during this campaign. Of these, the number of individuals that required an intervention (either control or biopsy/excision), that agreed to participate, that we were able to contact, and that ended up with a biopsy was 116 (see Fig. 1). Out of these 116 histologies we were able to get the written report in 66 (56.9\%). Our absolute detection rate for melanoma of $0.29 \%$ is very similar to that of the large Euromelanoma campaign published recently [3]. The positive predictive value of 0.72 also compares favorably with those published previously [3-5]. Although we had a relatively small number of follow-ups, interestingly, 2 out of 7 screenees (29\%) with $>100$ nevi had a melanoma, whereas only 6 out of $59(10 \%)$ with $<100$ nevi were diagnosed with melanoma (data not shown), recapitulating the significantly higher risk for melanoma in patients with high numbers of nevi [6].

Skin cancers are ideal for secondary prevention, meaning early diagnosis, because they are accessible to a simple visual inspection of the skin, and biopsy or excision can be performed very easily with a high chance of cure if the excision is performed early when tumor thickness is low. The detection of skin cancer during this screening cam- paign is important and was our primary outcome measure. In addition, the media activity and publicity around the campaign has other important desired "side effects," raising awareness for primary and secondary prevention of skin cancers. Unfortunately, it is methodologically not easy to measure this effect.

On the other hand, prevention campaigns might also create anxiety in screenees, and potential overdiagnosis/ overtreatment with consecutive psychological stress for the patient needs to be addressed [7].

Over the last decades the incidence of melanoma has increased considerably [8]. On the other hand, we have not observed an increased mortality in the same period (with only slight alterations in therapeutic interventions until the introduction of check-point inhibitors) [9]. This raises the question of overdiagnosis, as in prostate and breast cancer [7]. Overdiagnosis in this context describes histologically true melanomas (not false-positive diagnoses) which, however, would never develop into late-stage life-threatening melanomas.

Overdiagnosed melanomas, therefore, are not falsepositive melanoma diagnoses, but as of today we have no prospective marker allowing us to separate overdiagnosed from potentially dangerous melanoma. It may, however, be important to consider this concept of overdiagnosed melanoma when assessing the relatively high numbers of melanoma diagnoses in this and other studies [3], which reflects approximately a 16-fold increase in the population of screenees compared with the general population.

Skin cancer awareness and prevention campaigns have been performed for many years throughout the entire world. The Euromelanoma campaign exists since 1999 [5, 10]. It has rapidly spread across the entire continent of Europe and is now active in 33 countries. So far more than 450,000 people have received free skin screenings [11]. The data are analyzed on a regular basis and are a very valuable source for such epidemiological research $[4,5]$. The data from prevention campaigns in Switzerland were analyzed and published in the past as well. According to the authors, in the last evaluation from 2003 a total of 108 malignant lesions (21 melanomas) were detected in a total of 3,662 screened individuals (2.9\%) [12]. There have been efforts to measure the precise outcome of skin cancer prevention campaigns. Bulliard et al. [13] asked skin cancer screening campaign participants, who required lesion excision, for their personal data and correlated this with the data of the cancer registry. This approach has, in our opinion, limitations because there was no information on how many participants refused to participate,
4

Dermatology

DOI: $10.1159 / 000484946$
Braun/Ulrich/Hunger/Gaide/Arnold/ Merat/Dummer/Hafner/French/Cozzio 
how many ended up not seeing a physician, and how many of the treated lesions were not entered in the cancer registry database. From the 38 participants with suspected melanoma, they were able to trace 4 cases of histologically proven melanomas.

The problem with the evaluations of many prevention campaigns in the past is that the diagnosis made by the screening physician was considered to be the true diagnosis [12]. However, the problem of melanoma imitators and overdiagnosed melanomas is an ongoing clinical challenge for every dermatologist $[7,14,15]$. In fact, this is a problem, because it is difficult to evaluate the efficacy and cost-effectiveness of this type of large public prevention campaign without a precise solid outcome measure (e.g., number of histologically proven nonmelanoma skin cancers and melanomas per number of screenees during the campaign). Consistent with this, many public health decisions regarding prevention campaigns and budgets may have been taken in the past based on these "hypothetical" diagnoses.

Skin cancer screening of an unselected population is discussed controversially. The Cancer Council of Australia concludes that there is no evidence to recommend routine skin screening for skin cancer (Clinical Practice Guidelines for the Management of Melanoma 2008 [16]) while the American Cancer Society supports this type of regular screening [reviewed in 17]. However, there is also recent evidence from the literature that this type of largescale population screening is able to reduce mortality from melanoma at least by half [18-20]. This impressive reduction in mortality has also been shown in the pilot study of a small area of Germany (Schleswig-Holstein), whereas the follow-up study involving a much larger area was not able to confirm this [21].

Currently there is no randomized controlled trial which formally proves that skin cancer screening does more benefit than harm, and in the lack of evidence this is discussed very controversially and very emotionally. The fact is that we still do not know [22-24].

Even though many efforts have been made in the past, there is a need for data analysis regarding public screening for skin cancer. A recent publication of a Cochrane review protocol on this topic outlines a review that may provide invaluable information on mortality data, overdiagnosis, and psychological impact of screening activities for melanoma, focusing on randomized controlled trials comparing screening for melanoma with no screening, regardless of screening modality or setting [25].

So, the important question here is whether we screen the right people, i.e., whether we really reach out to the

National Swiss Skin Cancer Screening

Campaign 2013 risk population which we would otherwise miss. This answer is probably no. In this campaign there was no preselection of participants. Over the last couple of years, we observed the phenomenon that the same individuals would participate every year: in order to save money for a regular doctor's appointment, many people would take advantage of the free skin cancer screening and do their annual checkups during the screening campaign. While we appreciate our returning screenees, we would prefer to find a way to screen a higher percentage of high-risk individuals that would otherwise not see a dermatologist. This could be achieved through a process of preselection, e.g., via telephone interview or online questioning of the potential screenee for risk situations such as number of nevi, age, profession, or sun exposure during childhood. Taken together, in our study, we made an effort to trace down the correct final histological diagnosis by contacting screenees who agreed to be contacted. Despite this effort, we had an important dropout rate, as out of 402 cases (excision/biopsy required), only $66(16.4 \%)$ could finally be evaluated based on anonymized copies of the pathology report. We are currently investigating the reasons for this low rate in order to optimize the return rate of information in future campaigns. This may in turn help in better preselecting the screening population for skin cancer in a setting of increasingly limited medicoeconomic resources. So, in summary, we were not able to answer the question of whether we do the right thing. We believe that the only way to address this question would be via an international randomized controlled trial. In the meantime, until we have the results of this trial, we still have to carry out some prevention activities and raise the awareness of skin cancer in the population.

\section{Key Message}

The costs of free screening programs compare favorably with the prevented potential therapeutic costs of late-stage melanoma.

\section{Statement of Ethics}

Ethics approval was not necessary according to Swiss Human Research Act.

\section{Disclosure Statement}

The authors have no conflict of interest relevant to this study.

Dermatology

DOI: $10.1159 / 000484946$ 


\section{References}

1 Guy GP Jr, Ekwueme DU, Tangka FK, Richardson LC: Melanoma treatment costs: a systematic review of the literature, 1990-2011. Am J Prev Med 2012;43:537-545.

2 Freedberg KA, Geller AC, Miller DR, Lew RA, Koh HK: Screening for malignant melanoma: a cost-effectiveness analysis. J Am Acad Dermatol 1999;41:738-745.

3 van der Leest RJ, de Vries E, Bulliard JL, Paoli J, Peris K, Stratigos AJ, Trakatelli M, Maselis TJ, Situm M, Pallouras AC, Hercogova J, Zafirovik Z, Reusch M, Olah J, Bylaite M, Dittmar HC, Scerri L, Correia O, Medenica L, Bartenjev I, Guillen C, Cozzio A, Bogomolets OV, del Marmol V: The Euromelanoma skin cancer prevention campaign in Europe: characteristics and results of 2009 and 2010. J Eur Acad Dermatol Venereol 2011;25:1455-1465.

4 Forsea AM; Euromelanoma Working Group, del Marmol V: Impact, challenges and perspectives of Euromelanoma, a pan-European campaign of skin cancer prevention. J Eur Acad Dermatol Venereol 2013;27:1317-1319.

5 Stratigos AJ, Forsea AM, van der Leest RJ, de Vries E, Nagore E, Bulliard JL, Trakatelli M, Paoli J, Peris K, Hercogova J, Bylaite M, Maselis T, Correia O, Del Marmol V: Euromelanoma: a dermatology-led European campaign against nonmelanoma skin cancer and cutaneous melanoma. Past, present and future. Br J Dermatol 2012;167(suppl 2):99104.

6 Argenziano G, Giacomel J, Zalaudek I, Apalla Z, Blum A, De Simone P, Lallas A, Longo C, Moscarella E, Tiodorovic-Zivkovic D, Tiodorovic J, Jovanovic DL, Kittler H: Twenty nevi on the arms: a simple rule to identify patients younger than 50 years of age at higher risk for melanoma. Eur J Cancer Prev 2014;23: 458-463.

7 Welch G, Schwartz L, Woloshin S: Overdiagnosed - Making People Sick in the Pursuit of Health. Boston, Beacon Press, 2011.
8 Garbe C, Leiter U: Melanoma epidemiology and trends. Clin Dermatol 2009;27:3-9.

9 Nørgaard C, Glud M, Gniadecki R: Are all melanomas dangerous? Acta Derm Venereol 2011;91:499-503

10 Del Marmol V: The Euromelanoma campaign. Actas Dermosifiliogr 2016;107:365.

11 Euromelanoma. http://www.euromelanoma. org/intl (accessed August 31, 2017).

12 Bulliard JL, Levi F, Panizzon RG: The 2003 "Solmobile" prevention campaign for skin cancers of the Swiss League against Cancer: results and stakes (in French). Rev Med Suisse Romande 2004;124:237-240.

13 Bulliard JL, Maspoli M, Panizzon RG, Hohl D, Gueissaz F, Levi F: Evaluation of the Euromelanoma skin cancer screening campaign: the Swiss experience. J Eur Acad Dermatol Venereol 2008;22:365-366.

14 Braun RP, Rabinovitz HS, Oliviero M, Kopf AW, Saurat JH: Dermoscopy of pigmented skin lesions. J Am Acad Dermatol 2005;52: 109-121.

15 Braun RP, Saurat JH, French LE: Dermoscopy of pigmented lesions: a valuable tool in the diagnosis of melanoma. Swiss Med Wkly 2004; 134:83-90.

16 Australian Cancer Network Melanoma Guidelines Revision Working Party: Clinical Practice Guidelines for the Management of Melanoma in Australia and New Zealand. Wellington, Cancer Council Australia and Australian Cancer Network, Sydney and New Zealand Guidelines Group, 2008.

17 Tripp MK, Watson M, Balk SJ, Swetter SM, Gershenwald JE: State of the science on prevention and screening to reduce melanoma incidence and mortality: the time is now. CA Cancer J Clin 2016, Epub ahead of print.

18 Geller AC, Greinert R, Sinclair C, Weinstock MA, Aitken J, Boniol M, Capellaro M, Dore JF, Elwood M, Fletcher SW, Gallagher R, Gandini S, Halpern AC, Katalinic A, Lucas R,
Marghoob AA, Nolte S, Schuz J, Tucker MA, Volkmer B, Breitbart E: A nationwide population-based skin cancer screening in Germany: proceedings of the first meeting of the International Task Force on Skin Cancer Screening and Prevention (September 24 and 25, 2009). Cancer Epidemiol 2010;34:355358.

19 Katalinic A, Waldmann A, Weinstock MA, Geller AC, Eisemann N, Greinert R, Volkmer B, Breitbart E: Does skin cancer screening save lives? An observational study comparing trends in melanoma mortality in regions with and without screening. Cancer 2012;118: 5395-5402.

20 Schneider JS, Moore DH 2nd, Mendelsohn ML: Screening program reduced melanoma mortality at the Lawrence Livermore National Laboratory, 1984 to 1996. J Am Acad Dermatol 2008;58:741-749.

21 Boniol M, Autier P, Gandini S: Melanoma mortality following skin cancer screening in Germany. BMJ Open 2015;5:e008158.

22 Shellenberger R, Nabhan M, Kakaraparthi S: Melanoma screening: a plan for improving early detection. Ann Med 2016;48:142-148.

23 Wernli KJ, Henrikson NB, Morrison CC, Nguyen M, Pocobelli G, Blasi PR: Screening for skin cancer in adults: updated evidence report and systematic review for the US Preventive Services Task Force. JAMA 2016;316: 436-447.

24 Brunssen A, Waldmann A, Eisemann N, Katalinic A: Impact of skin cancer screening and secondary prevention campaigns on skin cancer incidence and mortality: a systematic review. J Am Acad Dermatol 2017;76:129139.e110.

25 Johansson J, Brodersen J, Gøtzsche PC, Jørgensen KJ: Screening for reducing morbidity and mortality in malignant melanoma. Cochrane Database Syst Rev 2016;9: CD012352. 